\title{
EL CONCEPTO DE LA MUERTE EN LA OBRA DE JOSÉ MARÍA ARGUEDAS Y SU RELACIÓN CON LO REAL MARAVILLOSO
}

* Reynaldo Oscar Santa Cruz Cabrera es licenciado en Sociología por la Universidad de San Martín de Porres y magíster en Literatura por la Universidad Nacional Mayor de San Marcos. Se desempeńa como docente en la Universidad de Lima y fue coordinador de Arte y Humanidades en la Universidad San Ignacio de Loyola. Asimismo, es miembro del Colegio de Sociólogos del Perú como también del Gremio de Escritores del Perú. Ha publicado libros de ficción y ensayos, por los que ha obtenido reconocimientos a nivel nacional como en el extranjero. Su obra, Monólogo nostálgico sobre La Habana, fue adaptada al cine en los Estados Unidos, bajo el título Alone y participó en el Festival Internacional de Miami en 2015. 
Resumen: El tema del artículo gira en torno a la visión de la muerte que propuso en su obra, el narrador peruano José María Arguedas, dando preferencia al análisis del cuento "La agonía de Rasu-Niti" (1962) y a su relación con el enfoque de lo Real Maravilloso. La metodología de trabajo consistió en la exploración del mencionado relato y la revisión de diversos estudiosos que ahondaron en este tópico de la estética arguediana, proponiendo una lectura que considerara los aspectos literarios y culturales de su singular perspectiva. En ese sentido, la estructura del artículo tomó en cuenta en primer lugar una breve contextualización sobre el concepto de la muerte desde la óptica de lo Real Maravilloso Latinoamericano, para luego centrarse en la descripción y ejemplificación de dicho aspecto, en el relato citado. Cabe resaltar en la interlínea, la intención de proponer al cuento en mención como un ejemplo representativo de la visión de la muerte en la narrativa de Arguedas. Finalmente, se concluye que "La agonía de Rasu-Niti" presenta una serie de rasgos que emparentan a Arguedas con el movimiento continental denominado lo Real Maravilloso, gracias a la percepción de la muerte que exhibe.

Palabras clave: Muerte, Real Maravilloso, Rasu-Nitit, Latinoamérica.

\title{
THE CONCEPT OF DEATH IN THE WORI OF JOSÉ MARÍA ARGUEDAS AND HIS RELATIONSHIP TO "LO REAL MARAVLLOSO"
}

\begin{abstract}
The article examines the vision of death proposed in the work of the Peruvian writer José María Arguedas, specifically in the analysis of the story "La agonía de Rasu-Niti" (1962), and its relationship with the approach to "lo real maravilloso". The methodology of the work consisted in a revision done by various scholars who delved into the topic of the Arguedian aesthetic, that led to the exploration of the mentioned story, proposing a reading that takes into account the literary and cultural aspects of its singular perspective. The structure of the article begs a brief contextualization of the concept of death from the perspective of the Latin American "real maravilloso". Following must be a focus on the description and exemplification of death in the aforementioned story. It should be noted the intention behind proposing the story in question is to demonstrate it as a arepresentative example of the vision of death in Arguedas' narrative. Finally, it is concluded that "La agonía de Rasu-Niti", thanks to the perception of death that it exhibits, shows several features that approach Arguedas to the continental movement called "lo Real Maravilloso".
\end{abstract}

Keywords: Death, Real Maravilloso, Rasu-Niti, Latin America. 


\section{Introducción}

$\mathrm{E}$

n Latinoamérica la vida y la muerte no solo conviven sino que son expresiones levemente diferenciadas de lo mismo y actúan como una sola en un devenir que solo atribuye a la segunda cierta mayor amplitud de desplazamientos y de comunicación. De esta forma, los ritos mortuorios de las civilizaciones precolombinas denotaban una mayor compenetración entre los deudos y el fallecido que los vínculos desarrollados por la cultura occidental y sus muertos más allá de estatuas o monumentos. Así queda demostrado con las ofrendas que acompañan al finado en su largo viaje, al igual que la tendencia al embalsamamiento, que implicaba un respeto a la imagen que el difunto tuvo en vida y al deseo de que esa apariencia física permanezca inalterada o por lo menos se retarde el proceso de deterioro que pudiera sufrir.

Siglos más tarde, los rezagos de aquellos rituales, transculturados por la conquista y por los vastos movimientos migratorios — casi nunca de retorno- han motivado una concepción del mundo y de las cosas, en la que los fantasmas, aparecidos o espectros intervienen de manera decisiva en el mundo de los vivos. Lo expuesto se hace patente en la forma en la que apelamos a los muertos para solicitar su intervención ante una dificultad o para invocar su poder y conseguir algún anhelo personal. En síntesis, nos dirigimos a ellos generalmente seres queridos o familiares - como a divinidades menores, una suerte de dioses domésticos, que por sus propias posibilidades o por su capacidad de intermediarios ante el Dios mayor poseen la virtud de solucionar nuestros problemas o al menos de intentarlo. En el otro extremo, los difuntos — generalmente ajenos, desconocidos- tienen la energía y la voluntad suficientes para atemorizarnos, ya sea profiriendo sonidos o movilizando objetos en un intento de intimidación sicológica. Esto lo percibimos en esa actitud subconsciente por la cual atribuimos a cualquier desplazamiento de lo inanimado o a alguna voz o grito, el carácter de lo fenecido, una emanación de ultratumba, etc.

Dicha relación estímulo-respuesta, que yace en el abismo de nuestro inconsciente colectivo y, por lo mismo, es parte del imaginario popular latinoamericano, se transporta a la literatura a través de episodios y sucesos ubicados en la nueva narrativa. Dentro de ese contexto, uno de los aspectos más importantes de la obra de José María Arguedas es el concepto de la muerte. La multiplicidad de opiniones y el debate entre términos que guardan una estrecha relación es el común denominador acerca del tema. Se han plasmado propuestas sesgadas y periféricas. Ninguna de las investigaciones citadas tiene como centro 
de su preocupación al vínculo establecido entre José María Arguedas, lo Real Maravilloso y la decisiva prueba de ello que significa "La Agonía de Rasu-Niti".

\section{Metodología}

\es lineamientos de la estrategia analítica son diversos, pero al mismo tiempo poseen
jerarquías de acuerdo a su importancia dentro del enfoque escogido. Tanto el método inductivo como el deductivo permiten en sus diferentes niveles, una gran variedad de registros y tonos aproximativos, ya que partir de lo general para llegar a lo particular y viceversa, no conforman como se podría pensar una dicotomía o en el mejor de los casos una dualidad sino por el contrario, resultan las dos facetas de un mismo proceso.

Todo ello explica el sentido totalizador de la presente propuesta, además será útil para organizar la armazón de la investigación. Asimismo, las fuentes de documentación del trabajo serán básicamente bibliográficas, pero no por ello se desterrará la experimentación empírica y las analogías con lo cotidiano, en la búsqueda de tópicos o expresiones recurrentes que configuren, por lo mismo, una coincidencia entre el referente real y su manifestación artística. Estos procedimientos son los más adecuados para ingresar a la producción arguediana.

\section{Elementos constitutivos}

\subsection{Paratexto y contexto}

En el paratexto revelador que es el título del cuento, "La agonía de Rasu-Nitit”, por ejemplo, nos preparan para el deterioro y el desenlace del danzante, mas no para el final, pues este no existe en la cosmovisión arguediana. El proceso de deterioro se manifiesta así desde las primeras líneas y es percibido como algo natural o como una etapa, en el largo recorrido de la existencia: "Estaba tendido en el suelo sobre una cama de pellejos. Un cuero de vaca colgaba de uno de los maderos del techo. Por la única ventana que tenía la habitación, cerca del mojinete, entraba la luz grande del sol” (Arguedas, 2004, p. 472).

Si bien el danzante aparece postrado, no se siente tristeza o melancolía, ni en la atmósfera ni en las descripciones. Es más, la aparición del sol, en todo su esplendor, confiere a la escena inicial del cuento una atmósfera de alegría, luz y vitalidad. No debemos ignorar la importancia del astro en nuestra antigua historia, lo que afianza el tinte mesiánico que 
el relato y el tono del narrador le imprimen: "El corazón está listo. El mundo avisa. Estoy oyendo la cascada de Saño. ¡Estoy listo! Dijo el dansak Rasu-Ńiti” (Arguedas, 2004, p. 472).

A pesar del significado de las fuerzas naturales (el poderoso sol o el sonido de la cascada, como heraldos de la muerte), el danzante está entusiasmado y poseído por un vigor repentino. No es la razón, el sometimiento, la resignación las que se abaten sobre el danzante y lo impelen a escenificar su último baile; es el corazón el que le anuncia la proximidad del fin, es un sentimiento poderoso el que anima la despedida de Rasu-Nititi:

- ¡Esposo! ¿Te despides?- preguntó la mujer, respetuosamente, desde el umbral. Las dos hijas lo contemplaron temblorosas.

- El corazón avisa, mujer. (Arguedas, 2004, p. 473)

Aquí se ratifica ese llamado que Rasu-Niiti escucha, no de una voz imperativa y externa que lo maneja de manera fatalista, como en el Antiguo Testamento cristiano, sino que ese impulso brota de su interior y no pretende ser un mandato bíblico; todo lo contrario, no pierde de vista su condición de presagio:

- (...) ¿A dónde está el sol? Ya habrá pasado mucho del centro del cielo.

- Ha pasado. Está entrando aquí. ¡Ahí está! (Arguedas, 2004, p. 473)

El Sol, aunque es un fenómeno externo, adquiere la soberanía ancestral que subsiste en la mentalidad andina y apura al danzante a cerrar su ciclo. El Sol se transforma así en el principio y final de las cosas. Es el astro que ilumina la mañana (el nacimiento) y que se oculta durante la noche (la muerte) y que esta vez, haciendo una excepción, alumbra la propia muerte de Rasu-Niti:

- ¡Ya estoy llegando! ¡Estoy por llegar! - dijo con voz fuerte el bailarín, pero la última sílaba salió como traposa, como de la boca de un loro. Se le paralizó una pierna. (Arguedas, 2004, p. 477) 
Además de la analogía con el loro — dicho sea de paso, la afinidad con los pájaros y los insectos voladores es una constante en la obra de Arguedas - es notoria la energía del dansak'. Anuncia que llega, pero ¿A dónde?, Especulando de acuerdo al contexto, podemos concluir que llega a la muerte, y en esa travesía, su cuerpo pierde la vida por etapas, en un ciclo irreversible.

El arpista cambió la danza al tono de waqtay (la lucha). "Rasu-Ñiti" hizo sonar más alto las tijeras. Las elevó en dirección del rayo del sol que se iba alzando. Quedó clavado en el sitio; pero con el rostro aún más rígido y los ojos más hundidos, pudo dar una vuelta sobre su pierna viva. Entonces sus ojos dejaron de ser indiferentes; porque antes miraba como en abstracto, sin precisar a nadie. Ahora se fijaron en su hija mayor, casi con júbilo. (Arguedas, 2004, p. 477)

Es conmovedora la lucha del danzante, pero no contra la muerte, (por el temor del fallecimiento, que no existe), sino contra la rigidez, contra la inmovilidad, que le impide desplazarse y cumplir con la función para la que fue elegido, su razón de ser. La presencia de la hija mayor le otorga el ánimo necesario y lo revitaliza: "Le faltaba ya saliva. Su lengua se movía como revolcándose en polvo (...) y cayó al suelo. Sentado. No dejó de tocar las tijeras. La otra pierna se le había paralizado” (Arguedas, 2004, pp. 477-478).

El paulatino deterioro de las funciones del dansak' solo engrandece su figura y la fortaleza de espíritu que lo anima, representado por el wamani. En ningún momento y a pesar de su desmoronamiento físico, Rasu-Níiti deja de tocar las tijeras. La ausencia de saliva revela su asfixia y aun con la pierna paralizada que lo hizo caer, continúa con su arte.

"Rasu-Ñiti" seguía con la cabeza y las tijeras este ritmo denso. Pero el brazo con que batía el pañuelo empezó a doblarse; murió. Cayó sin control, hasta tocar la tierra. Entonces "Rasu-Niiti” se echó de espaldas. (Arguedas, 2004, p. 478) 


\section{EL CONCEPTO DE LA MUERTE EN LA OBRA DE JOSÉ MARÍA ARGUEDAS Y SU RELACIÓN \\ CON LO REAL MARAVILLOSO}

En el texto queda claro que "Rasu-Niti" cayó, pero sabedor del proceso de paralización de sus miembros, se recostó para continuar el rito milenario. Ya la primera pierna había perdido la movilidad, era inexorable que la otra corriera la misma suerte. De esta manera, el venerable danzante se postró para no interrumpir más su baile de despedida:

A la hija menor le atacó el ansia de cantar algo. Estaba agitada, pero como los demás, en actitud solemne. Quiso cantar porque vio que los dedos de su padre que aún tocaba las tijeras iban agotándose, que iban también a helarse. Y el rayo de sol se había retirado casi hasta el techo. El padre tocaba las tijeras revolcándolas un poco en la sombra fuerte que había en el suelo. (Arguedas, 2004, p. 479)

A pesar de lo triste de la escena — para un observador foráneo- en realidad existe mucha solemnidad y respeto y el impulso de la hija por cantar está motivado por el amor filial, pero al mismo tiempo por el deseo de prolongar el rito. El canto, como ya se ha mencionado, ha acompañado al hombre andino en todos los aspectos de su vida. Desde los alegres y festivos, hasta los tristes y solemnes, como es la despedida de un ser querido. El canto acerca a la hija menor a las divinidades, sean estas de cualquier tipo: el río grande o su padre poseído por el wamani y divinizado coyunturalmente.

"Rasu-Niti” dejó caer las tijeras. Pero siguió moviendo la cabeza y los ojos (...) "Rasu-Niti" movió los ojos; la córnea, la parte blanca, parecía ser la más viva, la más lúcida. No causaba espanto. La hija menor seguía atacada por el ansia de cantar, como solía hacerlo junto al río grande, entre el olor de flores de retama que crecen a ambas orillas. Pero ahora el ansia que sentía por cantar, aunque igual en violencia, era de otro sentido. ¡Pero igual en violencia! (Arguedas, 2004, p. 479)

El detalle de la violencia parece contradictorio con respecto a la solemnidad del momento. Sin embargo, acentúa la fuerza telúrica que anima a Rasu-Nititi, además de 
relacionarse con las convulsiones del danzante. Todas las fuerzas que el hombre andino respetaba y en las que creía se unen como en una sinfonía: Wamani, canto, danza, ritual, ceremonia; fe, destino, muerte, vida..., aparecen una tras otra, para sacudir la escena y dotarla de la grandiosidad que merece:

El ojo del bailarín moribundo, el arpa y las manos del músico funcionaban juntos; esa música hizo detenerse a las hormigas negras que ahora marchaban de perfil al sol, en la ventana (...), Rasu-Ñiti cerró los ojos. Grande se veía su cuerpo. La montera le alumbraba con sus espejos. (Arguedas, 2004, p. 479)

El danzante, el instrumento musical y el intérprete, mantienen una sincronía perfecta, están conectados por un poder que los manipula para sus propósitos.

Finalmente, Rasu-Niti muere. Lo curioso es que recién cuando fallece se describe su estatura, sea esta real o solo la apariencia que tiene. Da la impresión de haber sufrido un desarrollo inverosímil, un crecimiento simbólico al morir. Luego, de forma abrupta, su discípulo irrumpe en la escena:

"Atok'Sayku" saltó junto al cadáver. Se elevó ahí mismo, danzando; tocó las tijeras que brillaban. Sus pies volaban. Todos lo estaban mirando. "Lurucha" tocó el lucero kanchi (alumbrar de la estrella), del wallpawak’ay (canto del gallo) con que empezaban las competencias de los dansak' a la medianoche. (Arguedas, 2004, p. 480)

La intempestiva aparición del danzante joven al lado del cadáver del danzante muerto, sugiere algo mágico. Por otro lado, su elevación, aunque explicable, y sus pies voladores, que podrían ser parte del lenguaje figurado que utiliza el narrador, no impiden que sea interesante el manejo de la atmósfera en un momento crucial.

La muerte no es tal porque la tradición continúa, el espíritu abandona el cuerpo viejo y sigue viviendo en el cuerpo joven del novel dansak'. Tradición y modernidad, viejo 


\section{EL CONCEPTO DE LA MUERTE EN LA OBRA DE JOSÉ MARÍA ARGUEDAS Y SU RELACIÓN \\ CON LO REAL MARAVILLOSO}

orden y nuevo orden, son solo etiquetas para intentar conceptualizar esta alegoría de la herencia cultural andina.

"Lurucha" inventó los ritmos más intrincados, los más solemnes y vivos.

"Atok' Sayku" los seguía, se elevaban sus piernas, sus brazos, su pañuelo, sus espejos, su montera, todo en su sitio. Y nadie volaba como ese joven dansak'; dansak' nacido. (Arguedas, 2004, p. 480)

El júbilo por este renacimiento se expresa de forma muy clara, puesto que el músico se esmera en tocar una melodía compleja y aparentemente contradictoria, pues los adjetivos, solemne y vivo dan la impresión de ser opuestos, sin embargo en el ritual se convierten en una sola entidad. El término vivos destaca en este instante de continuidad y legado y es refrendado por la otra palabra clave del fragmento: "Nacido". Así, el instante fronterizo entre muerte y vida, se plasma de forma muy objetiva aquí:

Enterraremos mañana al oscurecer al padre "Rasu-Ñiti".

- No muerto. ¡Ajajayllas! —exclamó la hija menor—. No muerto. ¡Él mismo! ¡Bailando! (Arguedas, 2004, p. 480)

Por si fuera necesario confirmarle al receptor del cuento la continuación del legado ancestral y la condición de la muerte como solo una fase o una etapa que no implica finitud, la intervención de la hija del danzante sella de manera definitiva, todo lo propuesto en esta hipótesis.

El otro aspecto que puede ser asociado al tema de la muerte, y que contribuye con la contextualización de la historia, es el de utilizar a los insectos como objetos-símbolo (tópico ya expuesto por Arguedas en otros momentos). Del mismo modo, la recurrencia para enfatizar la coloración de los insectos, aporta a la atmósfera alegórica del contexto.

Podía verse cómo varias hormigas negras subían sobre la corteza de lambras que aún exhalaba perfume. (Arguedas, 2004, p. 472; las cursivas son nuestras) 
Sobre el fuego del sol, en el piso de la habitación, caminaban unas moscas negras. (Arguedas, 2004, p. 473; las cursivas son nuestras)

Tardará aún La chirrinka que viene un poco antes de la muerte. Cuando llegue aquí nos vamos a oírla aunque zumbe con toda su fuerza... (Arguedas, 2004, p. 473)

Esa música hizo detenerse a las hormigas negras que ahora marchaban de perfil al sol, en la ventana. (Arguedas, 2004, p. 479; las cursivas son nuestras)

El color de los insectos, altamente connotativo, acentúa, como se mencionó previamente, la tensión y le da al texto el marco adecuado para el desarrollo del argumento. Si bien las hormigas son seres neutros en el mundo andino y carecen de significaciones, la chirrinka, en cambio, es conocida como la mosca de los muertos. De ese modo, los contrastes señalados entre la poderosa luz del sol que se refleja en el piso de la habitación y la tonalidad oscura de las moscas, reviste al contexto, de magia.

\subsection{Vida, muerte, madre; ejes temáticos}

Como se ha señalado algunas veces, Joseph Campbell considera también, como un factor clave, al elemento femenino. De la mujer engendradora a la que menciona Arguedas, surge como una consecuencia obvia, la madre, ya con nombre propio y creadora de todas las cosas, incluida la muerte. El artículo que la define, también es de carácter femenino: "La madre de la vida es al mismo tiempo la madre de la muerte; está enmascarada en los feos demonios de la enfermedad y el hambre" (Campbell, 1972, p. 73).

Esta hermandad y afinidad entre la vida y la muerte ocupa un espacio en las creencias colectivas y posee un significado de cambio y renovación. Es esencial remarcar que la cosmovisión andina no es la única en percibir este instante fronterizo entre vivir y morir como un espacio de cambio, pero sí es esencial detenernos en la naturalidad con que se acepta la llegada de esta etapa, tantas veces ratificada en el mundo arguediano: 
Un paso más entre los antecedentes trazados, nos deja ante otro de los grandes atributos. En la simbología cosmogónica, morir implica renovar las formas perecederas o caducas. Dicho de otro modo, se celebra el misterio de la destrucción que es la vida. Así se explica que a muchos de estos seres — por no decir a todos - no les asuste la muerte. (Campbell, 1972, p. 76)

La muerte en estas circunstancias va más allá del simple proceso natural y encierra en sí misma el juego de oposiciones entre tradición y modernidad, viejo y nuevo orden y otras similares.

Asimismo, el tópico de las transformaciones, rasgo inherente de lo Real Maravilloso se expresa a través de la muerte y con ello confirma su naturaleza:

Recordemos finalmente que, con frecuencia, la muerte resulta un acto regenerador y transformativo. Es lo que sucede en el relato "La agonía de «Rasu-Niti»" (1962). En realidad, el anciano danzante expira para resucitar en un discípulo cuyas acrobacias causan admiración. Ahora, el joven atok' sayku retoma el espíritu del extinto maestro: "Era él, el padre "Rasu-Niti"», renacido, con tendones de bestia tierna (...) nadie volaba como ese joven dansak'; dansak' nacido. (Iraides Cruz, 1992, p. 40)

Ese proceso de resurrección no se cumple en el otro mundo. Es decir muere y continúa su tránsito consciente, más allá. No es en esa otra dimensión "vital” en la que el fallecido recupera su "vida", sino que retorna a nuestro mundo, sea de manera individual, propia o transformada en un espíritu que, a su vez, posee a una persona y la anima con su vitalidad.

Esta percepción de la muerte es plasmada en diversos textos arguedianos, pero donde se manifiesta de forma muy clara y natural es cuando se desea explicar el retorno de un muerto al mundo de los vivos. Lo curioso es que este episodio no causa sorpresa, ni genera algún sobresalto. Por el contrario, es asumido como algo perfectamente normal y hasta cumple con un requisito temporal: 
Y cuando moría un hombre, recordando también los tiempos muy antiguos decían: "Nuestro muerto ha de volver dentro de cinco días. Esperémoslo". Y lo esperaban, transcurridos los cinco días, el muerto aparecía. (Arguedas, 1996, p. 156)

Esta manera de experimentar la cercanía de la muerte, su llegada y posterior retorno a la vida, es una forma de relacionarse con ella como si lo hiciera con otro ser vivo o con una entidad perfectamente tangible y concreta. Ya no se coloca el hombre ante un poder superior; sumiso, como ante una fuerza invencible y que lo condena a un destino inexorable, sino que prácticamente coquetea con el mismo, casi como si lo hiciera con una mujer.

Al cortejar a la muerte, se le desafía y, en última instancia, se le derrota. El estoicismo de Rendón frente a la muerte — que constituye un rito de pasaje necesario para una vida nueva, como se ve en la agonía de Rasu-Niti- y las dimensiones simbólicas que ha adquirido hasta entonces lo hacen sobrepasar su condición de individuo... (Moore, 2003, p. 227)

Resulta sintomático que el hombre se defina como tal, en el encuentro con la muerte y sobre todo con su actitud, a la que la estudiosa define como estoica, pero que carece de ribetes trágicos. Ella estaría más vinculada a la fortaleza de espíritu y a la entereza humana que a la resignación efectiva, signo inequívoco de derrota. Además de ello, la muerte no llega a ser definitiva, desde el momento en el que se le considera un momento de continuidad.

La muerte desaparece como tal y se convierte en un nexo simbólico entre dos planos de la realidad. Se confirma desde las ciencias sociales este tránsito, a través de un comentario que sugiere la abolición de la muerte junto con su desaparición sugerida.

"Rasu-Niti" es la historia de un personaje muy andino: el dansak', el danzante. Lo que me interesa en el danzante son dos cosas muy elementales: el dansak', la condición de dansak', de bailarín de las tijeras, es una condición que no nace con el sujeto sino que nace con la transmisión que los wamanis hacen 
a una determinada persona. En realidad el dansak' nunca muere, porque el que muere es solamente el soporte del dansak' que es la persona humana, que finalmente se termina por transmitir a otros dansak' en el futuro. En este caso, en el cuento se produce la transmisión de la condición de dansak' a otro personaje que forma parte de este cuento, y es en realidad el wamani. Cuando muere el dansak' se traslada al siguiente dansak'. (Burga, 1995, p. 20)

La opinión de Burga confirma el legado ancestral que no se detiene; el ciclo mítico que se prolonga a través del tiempo y de los hombres. Pero existe algo más trascendente aún que lo referido y ello es el concepto que el científico social aquí reseñado posee del wamani: esta deidad ya no es solo la fuerza que inspira o motiva al danzante y colabora con su baile, sino que crea una auténtica posesión. Esto convierte al cuerpo del artista en un simple medio, una envoltura que cumple un período y luego es desechada.

La analogía con la cosmovisión religiosa del cristianismo es obligatoria y signa al wamani con todos los atributos que en el ámbito judeocristiano se le confiere al alma.

Miguel Ángel Huamán discrepa de la interpretación que generalmente se le da al relato como metáfora fatalista y la propone como lo opuesto. La supuesta denuncia social, también es desestimada por el mismo estudioso. En conclusión, comparte el concepto de la muerte que la cosmovisión andina propone y esboza algunas líneas temáticas que se presentan en la producción arguediana.

El texto como situación de discurso, como actividad comunicativa realiza un comportamiento solidario entre hablante y oyente, entre destinador y lector. Esto aparece claramente en el relato "la agonía de Rasu-Niti" donde la escritura ética en su proceso se asume como escritura utópica, igualando en diálogo imaginario ambas, el predominio del enunciado de la cultura dominante (referencialidad de la muerte o la división social), con el predominio de la enunciación de la cultura subordinada (reflexibilidad de la vida o continuidad cultural).

Aunque se ha querido ver en este relato nuevamente la violencia de la ausencia y la muerte, así como la denuncia social, nos encontramos ante lo contrario: el júbilo por la presencia y la vida. (Huamán, 1995, p. 290) 
Esta perspectiva de la muerte como un instante inevitable, pero en el sentido de natural proceso que confirma la humanidad, es representada por la alegría del hecho: algo o alguien acaba. No obstante, al mismo tiempo y por consecuencia, algo o alguien nace. Rasu-Ñiti muere, pero solo es una etapa previa para el "nacimiento" de Atok' sayku, a quien el wamani ha escogido para continuar el ritual”.

Siendo significativa la marca de continuidad que la escritura utópica como significante desencadena, pues el danzante no muere y continuará ejerciendo su cultura en cada nueva lectura: "por dansak' el ojo de nadie llora: Wamani es Wamani”. (Huamán, 1995, p. 290)

No hay dolor ante la muerte, es un acontecimiento inherente a la condición humana, tan natural como lo es el nacimiento. Si el nacimiento motiva júbilo, esperanza, alegría y celebración, es coherente que la muerte, que comparte la esencia del ciclo vital del hombre con la aparición en el mundo, cause igual regocijo: se cierra un ciclo y se abre otro. Esto en el mundo dual y cíclico andino es asumido como símbolo de continuidad, de supervivencia.

Huamán apoya su acertado comentario en la cita que efectúa de Blanca R. Montevechio, en su capítulo "Muerte y duelo en los Andes. Interpretación psicoanalítica de la agonía de Rasu-Niiti de José María Arguedas", que está incluido en su libro La identidad negativa. La metáfora de la conquista (Ed. Kargieman, Buenos Aires, 1991):

Ha sabido recalcar la diferencia ante la muerte que implica la cultura andina pues en ella la muerte no es el instante último, la pérdida irreparable, sino un momento esencial en el devenir del tiempo, donde no hay pérdida, ni culpabilidad o pecado. (Huamán, 1995, p. 290)

Esta opinión no hace otra cosa más que presentar un balance acerca del ideario indígena, en el que los términos, muerte, vida, nacimiento, culpa, etc. han sido resemantizados por intereses ideológicos y culturales. Es por todo ello que las lecturas que usualmente se 


\section{EL CONCEPTO DE LA MUERTE EN LA OBRA DE JOSÉ MARÍA ARGUEDAS Y SU RELACIÓN CON LO REAL MARAVILLOSO}

hacen del relato que nos ocupa, proceden de una mirada externa, occidentalizada, desde la que se aprehenden y se interpretan algunos niveles del imaginario andino, pero no todos:

Para la lectura tradicionalista "La agonía de Rasu-Ñiti" simplemente refiere la muerte de un danzante, en el mejor de los casos la persistencia de creencias ancestrales. Lo que prima en el texto no es la muerte ni la violencia, tampoco la pérdida o ausencia, sino el júbilo y la continuidad. (Huamán, 1995, p. 291)

El término júbilo, que reaparece en las apreciaciones de Huamán, está manejado con sapiencia, porque esta manifestación de alegría concuerda con los rituales fúnebres en los que los pueblos andinos despliegan toda una gama de sentimientos. La exaltación se ve reflejada en la danza y la música, y en la seguridad que la muerte es solo el instante previo a una nueva vida. Gracias a ello, en el imaginario andino, se manifiesta una resistencia a la finitud.

Debemos revisar, igualmente, el contexto espiritual y sicológico que rodeó a Arguedas durante la probable génesis de La agonía de Rasu-Niti; hasta qué punto el júbilo del que nos habla Huamán tuvo su contraparte en la propia psiquis del escritor y en su propio y radical concepto de despedida:

En una carta de 1962, que escribiera a la Dra. Hoffmann, Arguedas menciona "un cuento" que había escrito "con la idea de suicidarme, me despedí de la vida escribiendo ese relato que, como usted verá es más un canto a la vida que a la desesperación”. Lo más probable es que se tratara de la agonía de Rasu-Ñiti que fue escrito en 1961 y publicado en 1962. La muerte en este texto es una realidad física y espiritual que atraviesa todos los límites, todas las fronteras. Se acompaña por un momento de sosiego y silencio absoluto, en el que se siente hasta el caminar de las hormigas... (Rowe, 2006, p. 170)

El mundo andino que José María Arguedas construyó en la ficción y que posee vínculos ineludibles con el contexto en el cual vivió, no es ajeno a la noción que ocupa nuestra 
reflexión en este capítulo: “Esposo! ¿Te despides? -preguntó la mujer, respetuosamente, desde el umbral. Las dos hijas lo contemplaron, temblorosas" (Arguedas, 2004, p. 473).

Es revelador que los tres personajes que rodean al danzante sean mujeres y no exista un heredero masculino, directo, a quien Rasu-Niti pudiera adiestrar en el arte del baile de tijeras. Tanto la esposa que pregunta "respetuosamente", como las dos hijas que contemplan "temblorosas" a su padre, no pueden participar del ritual, excepto como observadoras. La danza de tijeras es un oficio de hombres y solo ellos pueden ser el centro del espectáculo y de la gloria que dicho arte proporciona al ejecutante. Las mujeres no desempeñan un ritual semejante y solo pueden colaborar de manera externa, como ayudantes circunstanciales y mecánicos, pues son mensajeras, o asistentes sin mayor trascendencia: "La mujer se inclinó ante el dansak'. Le abrazó los pies (...) Rasu-Ñiti, cuya presencia se esperaba, casi se temía y era luz de las fiestas de centenares de pueblos" (Arguedas, 2004, p. 473).

La actitud de la mujer es muy explícita y va más allá del cariño y de la ternura conyugal. El hecho de postrarse ante el danzante nos exime de una profundización en detalles. Las analogías son inevitables con reconocidas imágenes de la historia, en las que el patriarca ejercía una autoridad muy grande sobre sus mujeres.

Otra semejanza se encuentra en la actitud de subordinación que, ante los emperadores, monarcas y reyes, mostraban los súbditos. Este código está presente también en el universo religioso, puesto que toda figura patriarcal y signada por la autoridad que le otorga un puesto elevado en las jerarquías sacras — el Papa, por ejemplo-, suele inspirar gestos similares. De más está decir que, en gran parte de las religiones, los devotos se inclinan ante su dios, mesías o figuras cercanas en trascendencia.

La esposa de Rasu-Niti ratifica esta posición al abrazar los pies de su marido, en clara demostración de subordinación con respecto al danzante. Esta escena es seguida en el fragmento por una descripción del poder y la autoridad del danzak', que era reconocida, esperada y que casi infundía temor. Finalmente, y aunque es una figura literaria, él "iluminaba” las fiestas, adjetivo de gran carga mágica y simbólica: “-_Está el wamani! ¡Tranquilo! -exclamó la mujer del dansak’ porque sintió que su hija menor temblaba” (Arguedas, 2004, p. 477).

Si bien la esposa de Rasu-Ñiti asume la presencia del wamani, su hija no logra siquiera tal percepción y solo tiembla, como lo hizo anteriormente al lado de su hermana. Es incapaz de algún otro movimiento. El estereotipo que ha marcado a la mujer, atribuyéndole conductas timoratas y cobardes y que solo se ha transformado en un tristemente célebre 
calificativo: sexo débil, se exhibe una vez más: “¡El wamani aletea sobre su frente! — dijo Atok' sayku. -Ya nadie más que él lo mira -dijo entre sí la esposa- yo ya no lo veo" (Arguedas, 2004, p. 478).

Es lógico que el heredero y continuador de la tradición, el nuevo dansak', posea la cualidad de ver al wamani, pero no deja de ser significativo el hecho de que la mujer deje de distinguir su presencia y que además reconozca esa imposibilidad y la asuma con frustración, puesto que ella no la manifiesta abiertamente sino solo para sí misma; resignada, impotente: "Un cuy se atrevió también a salir de su hueco. Era macho, de pelo encrespado; con sus ojos rojísimos revisó un instante a los hombres y saltó a otro hueco. Silbó antes de entrar" (Arguedas, 2004, p. 478).

En el mundo andino los animales juegan un papel muy importante $y$, como se ha presentado en casi toda la obra de Arguedas, las connotaciones que pueden alcanzar por su coloración, actitudes o pretensiones de humanización, son decisivas en el estudio de su contexto. El animal citado aquí, el cuy, es macho y aunque podríamos concluir que se trata de una coincidencia por la ambigüedad de su aparición, esta misma ambigüedad nos permite inferir una intencionalidad que rebasa el terreno de las casualidades. El cuy no sale de su escondrijo con la típica conducta errática y temerosa, clásica en su especie, sino que "revisa" a los asistentes, en una acción observadora y tal vez, hasta evaluativa. Notemos que el animal pasa por alto a las mujeres presentes y solo mira o pasa revista a los hombres, corroborando así la mayor importancia de ellos con respecto a las mujeres. El detalle del silbido es un brillante recurso para afianzar esa atmósfera extraña y sobrecogedora.

Aunque rebasa los linderos del cuento estudiado, Arguedas, en su vida privada y tal vez por la ausencia materna, respetaba a la mujer y la veía con simpatía. Pero era esa una presencia pasiva observada a la distancia y con la que establecía un vínculo muy particular: "El trato que daba a la mujer y su comportamiento con ella, era algo así como ceremonioso, misterioso, como una cuestión un poco mágica. Era como si él estuviera frente a la virgen María” (Arredondo, 1992, p. 23).

Todo ello nos presenta una particular forma de comprender la esencia de la muerte y los elementos culturales que signan la obra de nuestro notable narrador. Enfoque que parte del imaginario popular andino y que Arguedas reproduce en su narrativa breve. 


\section{Discusión de resultados}

T a lectura y análisis del relato estudiado, bajo los parámetros de lo Real Maravilloso y del Ldenominado Neoindigenismo, reveló profundas coincidencias entre ambas tendencias literarias, lo cual sugiere que, con algunos matices, expresan variedades regionales del mismo procedimiento. La mención del espacio físico, es decir del territorio, solo sirve para definir leves diferencias en la enunciación del discurso. En síntesis, fuera de las particularidades lingüísticas en el plano de la forma, el del contenido manifiesta una identidad... común.

Un aspecto destacable es que el concepto de la muerte es muy representativo para mostrar la relación entre las dos perspectivas estéticas, pero de ningún modo es el único ni el más trascendente. Podríamos mencionar a las transformaciones como un célebre rasgo en común. Finalmente, los vasos comunicantes entre lo mágico y lo que asumimos como real, desempeña un papel central en las semejanzas estilísticas.

Por otro lado, se propuso la lectura preferentemente de un relato de José María Arguedas, pero este modelo investigativo se podría aplicar perfectamente a otros narradores latinoamericanos, para ratificar estos resultados, replicando así el presente experimento.

La tradición narrativa de nuestro continente, preferentemente mágico-social, confirma esta presunción. En último término, el mundo andino posee su propio sistema de creencias, el cual sin embargo, se asemeja a otros sistemas dentro de nuestro subcontinente.

\section{Conclusiones}

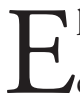
previamente mencionado sistema de creencias latinoamericano, opera en un nivel en el que las religiones canónicas y las supersticiones populares, se distinguen muy poco entre sí y giran en torno a un factor espiritual, denominado fe.

La resemantización de los códigos culturales de occidente, se manifiesta de forma muy clara en las diferentes lecturas que se aplican a la noción religiosa y al pensamiento mágico. Todo ello, da como lugar una trascendente asimilación de la muerte y por ello mismo de su opuesto, la vida, manifestado en las siguientes conclusiones:

Primero, la fe desbordada, cualquiera que sea su naturaleza, necesita mecanismos expresivos que puedan interpretarla y canalizarla. De allí que lo Real Maravilloso solo puede existir si a su vez existe una gran fe que lo haga posible y creíble; esa fe es el eje fundamental 


\section{EL CONCEPTO DE LA MUERTE EN LA OBRA DE JOSÉ MARÍA ARGUEDAS Y SU RELACIÓN \\ CON LO REAL MARAVILLOSO}

en el cuento analizado aquí. Los canales por donde discurren las creencias latinoamericanas son diversos y están presentes en todos los actos humanos.

Segundo, las interpretaciones religiosas del mundo occidental y en especial las teorías judeocristianas pueden sufrir una profunda transformación desde la perspectiva nativa y por lo tanto sus conceptos rígidos se ven violentados. La visión alternativa que propone la cultura latinoamericana, procede de las diversas sociedades que ocuparon este territorio. Cada grupo humano comparte una cosmovisión que muchas veces forzó el paradigma occidental.

Tercero, el entendimiento de la muerte en América Latina difiere del occidental y revela unas relaciones muy propias. Con lo que la dicotomía vida-muerte se convierte en un terreno difuso, perfecto por lo mismo para lo Real Maravilloso. En el universo narrativo de la cultura andina y en el de Arguedas en particular, la presencia del concepto de la muerte, es muy vigorosa.

\section{Referencias}

Arguedas, J. M. (2004). La agonía de Rasu-Ñiti. En Pinilla, C., „Kachkaniraqmi! jSigo siendo! José María Arguedas, textos esenciales (pp. 472-480). Lima, Perú: Fondo Editorial del Congreso del Perú.

Arguedas, J. M. (Trad.) (1996). Dioses y hombres de Huarochirí. Lima, Perú: Museo Nacional de Historia e Instituto de Estudios Peruanos.

Arredondo, S. (enero, 1992). Entrevista de Galo F. González. Anthropos, 128, pp. 21-26.

Burga, M. (1995). Un zorro que se creía erizo. En Martínez, M. \& Manrique, N. (comps.), Amor y fuego, José María Arguedas, 25 años después (pp. 15-22). Lima, Perú: Desco, Cepes, Sur.

Campbell, J. (1972). El héroe de las mil caras. Psicoanálisis del mito. México D.F., México: Fondo de Cultura Económica.

Huamán, M. A. (1995). Amor, goce y violencia en el relato arguediano. En Martínez, M. \& Manrique, N. (comps.), Amor y fuego, José Maria Arguedas, 25 años después (pp. 289-292). Lima, Perú: Desco, Cepes, Sur. 
Iraides Cruz, P. (enero, 1992). Arrojo y heroicidad en algunos personajes de José María Arguedas. Anthropos, 128, 40-42.

Moore, M. (2003). En la encrucijada, las ciencias sociales y la novela en el Perú. Lecturas paralelas de Todas las Sangres. Lima, Perú: Fondo Editorial de la Universidad Nacional Mayor de San Marcos.

Rowe, W. (2006). El lugar de la muerte en la creación del sujeto de la escritura. En Franco, S. R. (comp.), José María Arguedas, hacia una poética migrante (pp. 169-175). Pittsburgh, USA: Instituto Internacional de Literatura, Universidad de Pittsburgh. 